\title{
EKSPRESI CINTA \\ DALAM NOVEL SIRKUS POHON KARYA ANDREA HIRATA
}

\author{
(Expression of Love in Andrea Hirata's Sirkus Pohon)
}

\author{
Suryanti \\ Jalan P. Suriansyah 3, Loktabat Utara, Kota Banjarbaru, Kalimantan Selatan 70712 \\ Pos-el: keziayanti1511@gmail.com
}

(Naskah Diterima 10 Mei 2021—Direvisi 18 Agustus 2021—Disetujui 24 September 2021)

\begin{abstract}
The novel by Andrea Hirata describes the values of life society that are useful for readers in life. This article aims to describe the expression of love in the novel Sirkus Pohon. This is a qualitative descriptive research. The data is compiled by reading the novel, taking notes and analyzing each sequel containing expressions of love. The results of this study indicate that love is expressed for God, friends, family, peace, the surrounding community, the country, the environment and the opposite sex.
\end{abstract}

Keywords: love expression, Sirkus Pohon novel

\begin{abstract}
Abstrak
Novel karangan Andrea Hirata ini menggambarkan nilai-nilai kehidupan di tengah masyarakat. Nilai-nilai tersebut berguna bagi pembaca dalam menjalani kehidupan. Artikel ini bertujuan untuk mendeskripsikan ekspresi cinta dalam novel Sirkus Pohon. Penelitian ini merupakan penelitian deskriptif kualitatif. Data dikumpulkan penulis dengan membaca secara utuh novel, mencatat, dan menganalisis setiap sekuel yang mengandung ekspresi cinta. Hasil penelitian ini menunjukkan bahwa ekspresi cinta yang terdapat dalam novel tersebut ialah aspek cinta kepada Tuhan, sahabat, keluarga, cinta perdamaian, masyarakat sekitar, tanah air, lingkungan, dan lawan jenis.
\end{abstract}

Kata kunci: ekspresi cinta, novel Sirkus Pohon

\section{PENDAHULUAN}

Sastra adalah salah satu komponen dari karya seni kreatif yang mampu digunakan untuk mengumpulkan dan menyampaikan gagasan dan pemikiran manusia. Sastra merupakan sebuah interpretasi dan representasi masyarakat yang mencerminkan kehidupan di dalam lingkungan masyarakat itu.

Karya sastra dibuat agar dinikmati dan dimanfaatkan oleh masyarakat. Para sastrawan yang menciptakan suatu karya sastra disarankan dapat membawa pembacanya kepada suatu alam kenikmatan sehingga pembaca mampu meresapkan dan mendapatkan manfaat dari karya sastra yang dibaca.

Beragam rupa karya sastra menyajikan berbagai cerita yang dapat dijadikan suatu pembelajaran dalam kehidupan pembacanya. Novel adalah salah satu jenis karya sastra. Novel muncul dan mengalami perkembangan dengan sendirinya sebagai bentuk cerita dan menggambarkan realitas sosial. Penuturan tersebut diperkuat oleh Nurgiyantoro yang menjelaskan bahwa suatu novel adalah sebuah kepaduan yang utuh dan bersifat artistik. Paduan dari novel tersebut memiliki unsur yang 
saling berhubungan sehingga menjadi satu kesatuan dan tidak terpisahkan (Nurgiyantoro, 2010).

Novel karangan Andrea Hirata berjudul Sirkus Pohon membuat penulis tertarik untuk mengkajinya dari aspek ekspresi cinta. Ekspresi cinta lahir sebagai sebuah realitas kehidupan. Kehadirannya menjadikan sebuah gairah sekaligus permasalahan sebagaimana kehidupan itu sendiri.

Wattimena mengatakan bahwa cinta merupakan kumpulan perasaan, pernyataan, perilaku yang bermuara pada kasih sayang (Wattimena, 2014). Keadaan tersebut dapat diibaratkan sebagai emosi dari keinginan yang sangat kuat dan kasih sayang individu. Situasi itu dapat dijadikan sebagai sebuah kebajikan yang mewakili kebaikan seseorang, kesetiaan, dan perhatian, serta tidak bertindak egois demi seseorang yang dikasihi.

Cinta juga dapat mengimplikasikan respons kasih sayang yang tidak terbatas kepada manusia, binatang, atau tumbuhan. Suatu karya sastra yang menceritakan cinta mempunyai banyak pengagum dan pembaca. Hal itu disebabkan oleh cinta yang seolah-olah dapat dikonsumsi semua orang (Simangungsong, 2015).

Ekspresi cinta lahir ketika sepasang manusia merasa saling memiliki, saling menyayangi, dan saling setia. Tanpa kesetiaan, kasih sayang, rasa percaya, rela berkorban, dan kejujuran, hubungan cinta tidak akan berjalan dengan baik. Nilai cinta tidak selamanya sakral, tetapi dapat juga terjadi suatu demistifikasi, yaitu penurunan arti dari cinta. Cinta yang sangat luar biasa berubah menjadi cinta yang biasa saja (Sarwiningsih, 2013).

Masalah yang muncul dalam kehidupan manusia tentu tidak akan pernah usai. Banyak orang yang jiwanya menjadi kosong, hilang arah, hilang tujuan dalam hidup, stres, dan tidak mampu berpikir jernih karena tidak mampu menyelesaikan suatu masalah yang tengah dihadapi. Dalam keadaan seperti yang disebutkan, sebuah karya sastra dinilai memiliki peran yang mampu mendorong dan memberikan sebuah jawaban. Karya sastra juga mampu menjadi guru dalam kehidupan karena misi dari sastra itu sendiri ialah media yang urgent untuk para pemikir guna menggugah pembaca kepada suatu realitas serta membantu mengatasi suatu masalah yang belum terpecahkan (Siregar, 2013).

Novel Sirkus Pohon karya Andrea Hirata menceritakan Sobri dengan tokoh aku asal Tanjung Lantai, Belitong. Sobri merupakan pemuda penganggur. Pekerjaan Sobri tidak tetap, bekerja di tempat satu ke tempat lainnya, serabutan. Hal tersebut disebabkan oleh Sobri yang hanya lulusan SMP dan sangat kesulitan menemukan pekerjaan yang cocok (Hirata, 2017).

Sobri berkenalan dengan Dinda, seorang gadis Melayu. Dalam usaha pencarian kerja, Dindalah yang terus menyemangati Sobri untuk tidak putus asa. Suatu ketika, Sobri berhasil mendapatkan pekerjaan sebagai badut sirkus.

Novel ini banyak memuat pesan yang dapat diambil pembacanya. Pesan tentang kesabaran dalam sebuah penantian, tentang pengorbanan dalam sebuah hubungan, dan tentang sosial ekonomi, politik, serta budaya dapat memberikan referensi bagi para pembacanya.

Penulis mencoba menganalisis ekspresi cinta yang terkandung dalam novel tersebut. Penelitian ini bertujuan agar pembaca menemukan wujudwujud ekspresi cinta dalam novel Sirkus Pohon.

Penelitian yang dilakukan Sri Susetianingsih pada 2015 mengangkat 
sebuah novel karangan Tere Liye yang berjudul Bidadari-Bidadari Surga sebagai objek (Sri Susetianingsih, 2016). Terdapat perbedaan dalam pendekatan dan subjek penelitian antara penelitian yang dilakukan Sri Susetianingsih dengan yang dilakukan penulis. Pembahasan penelitian Sri Susetianingsih menggunakan pendekatan sosiologi sastra, sedangkan penelitian ini menggunakan pendekatan psikologi sastra. Penelitian terhadap novel Bidadari-Bidadari Surga menjadi pedoman penulis untuk selanjutnya meneliti ekspresi cinta dalam novel Sirkus Pohon.

\section{METODE PENELITIAN}

Penelitian ini merupakan penelitian deskriptif kualitatif dengan menggunakan kajian pustaka. Novel Sirkus Pohon diterbitkan di Yogyakarta pada tahun 2017. Teknik analisis data dilakukan penulis dengan membaca secara utuh novel Sirkus Pohon. Penulis kemudian mencatat dan menganalisis setiap sekuel yang mengandung ekspresi cinta.

Kajian penelitian ini difokuskan terhadap aspek psikologi sastra dengan menggali ekspresi cinta yang terdapat di dalam novel tersebut. Dengan pendekatan psikologi sastra, peneliti berusaha mendeskripsikan dan menjelaskan unsur-unsur perwatakan yang diambil dari teori Abraham $\mathrm{H}$. Maslow, yaitu aspek fisiologis, aspek rasa aman, aspek cinta dan rasa ingin saling memiliki, aspek penghargaan, dan aktualisasi diri yang didapatkan pada novel Sirkus Pohon.

\section{PEMBAHASAN}

Kebahagiaan hadir dalam suatu situasi ketika seseorang menjadi sangat berarti untuk seseorang yang mencintainya. Cinta dapat berwujud perasaan, pernyataan, dan perilaku yang berbeda dan bersumber dari kasih sayang. Kasih sayang tersebut dapat bermuara pada emosi, keinginan, serta kasih sayang.

Keadaan tersebut dapat diibaratkan sebagai emosi dari keinginan yang sangat kuat serta kasih sayang individu. Situasi itu dapat dijadikan sebagai sebuah kebajikan yang mewakili kebaikan seseorang, kesetiaan, perhatian, serta tidak bertindak egois demi seseorang yang dikasihi. Cinta pun dapat mengimplikasikan respons kasih sayang yang tidak terbatas kepada manusia, binatang, atau tumbuhan.

Adapun ekspresi cinta yang terdapat dalam novel Sirkus Pohon ialah sebagai berikut.

\section{Cinta kepada Tuhan}

Cinta kepada Tuhan merupakan konsekuensi keimanan. Tidak ada sesuatu yang harus dicintai pertama kali, kecuali cinta kepada Tuhan. Segala bentuk ibadah, penyembahan, dan ketaatan serta cinta yang mutlak hanyalah kepada Tuhan.

Telah menjadi fitrah manusia untuk mencintai dan dicintai. Untuk itu, nikmat akan dirasakan kepada keluarga, sahabat, bahkan kepada Tuhan. Manusia menyadari cinta kepada Tuhan merupakan cinta yang tidak biasa dan bukan sekadar mimpi.

Cinta kepada Tuhan mengharuskan setiap individu berbuat baik, jujur, dan bijak. Semuanya itu diusahakan oleh manusia demi mencapai puncak kenikmatan mencintai Tuhan. Esensi mencintai Tuhan didapatkan melalui kerja keras, menyembah, beribadah, serta mengingat Tuhan dalam tempat, kondisi, dan situasi apa pun sehingga tidak ada ruang dalam hatinya, melainkan hanya terdapat Tuhan.

Mencintai Tuhan dapat membuat hati sejuk dan tenteram. Tidak ada satu 
hal pun yang mampu menghiasi kehidupan suatu individu kecuali cintanya kepada Tuhan jika ia telah mencintai Tuhan. Itulah yang dinamakan hakikat cinta kepada Tuhan.

Dalam novel Sirkus Pohon terdapat tokoh yang mencintai Tuhan, yakni sosok Ibu. Hirata menggambarkannya dengan ungkapan "Ibu adalah seorang yang religius, sosok ibu dalam keadaan sehat ketika sebelum adzan Ashar beliau mandi dan membersihkan diri" (Hirata, 2017:5). Pernyataan tersebut mengindikasikan sosok yang cinta kepada Tuhan. Tokoh yang berperan sebagai ibu menyiapkan berbagai hal, seperti mandi untuk bersiap salat ashar. Hukum melakukan mandi sebelum melaksanakan salat ialah sunah. Kondisi tersebut merupakan sebuah perilaku yang menjurus kepada kebaikan dan keimanan kepada Tuhan dan dapat diteladani oleh setiap manusia untuk menaati ajaran agama Islam dengan mandi sebelum melakukan salat. Salat termasuk salah satu bentuk cinta tokoh ibu terhadap Tuhan.

\section{Cinta kepada Sahabat}

Cinta kepada sahabat adalah perasaan sehati, saling menghargai, saling toleransi, berbagi rasa, kesepahaman, dan kecocokan dalam berkomunikasi. Cinta kepada sahabat dalam novel Sirkus Pohon digambarkan oleh tokoh Taripol yang terlihat dalam kalimat berikut.

"Tak satu pun kulihat batang hidung mereka. Taripol lah yang membawaku ke puskesmas. Dengan persahabatannya yang tulus, dialah yang mengobati luka batin mendalam yang kualami garagara sapi cabul berkalung lonceng itu" (Hirata, 2017:18).

Dalam kutipan tersebut, ketika Sobrinudin terkena seruduk Boneng, seekor sapi jantan, tidak ada satu pun yang menolong, kecuali sahabatnya,
Taripol. Padahal, saat itu ada banyak orang di situ. Mereka justru menyalahkan Sobrinudin. Hanya Taripol lah yang peduli. Ini adalah bentuk cinta terhadap sahabatnya.

\section{Cinta kepada Keluarga}

Cinta kepada keluarga adalah perasaan setiap anggota keluarga untuk saling menyayangi, mengasihi, menghormati, serta saling memedulikan. Cinta kepada keluarga dalam novel Sirkus Pohon diilustrasikan dalam sosok Tegar.

Tegar menyatakan bahwa kehidupan seorang Tegar tidak sebaik keluarga-keluarga lainnya. Tegar adalah tulang punggung keluarganya walaupun ia masih berusia sangat belia, yakni 14 tahun. Tegar merupakan sosok yang mencintai keluarganya.

Tegar memahami dan mengerti kondisi kehidupan keluarganya saat itu. Ia menangkap situasi tersebut dengan cepat dengan cara bekerja agar hidup keluarganya berubah seperti keluarga lainnya. Ia menginginkan kehidupan keluarganya sama seperti sedia kala. Tegar harus bekerja, melakukan pekerjaan rumah, dan membantu sang adik belajar. Pada waktu yang sama, Tegar juga harus mencari nafkah dengan bertindak sebagai ayah sekaligus ibu demi keluarganya.

Ini adalah ekspresi cinta tokoh Tegar kepada keluarganya. Ekspresi cinta keluarga juga digambarkan tokoh Sobrinudin yang mengatakan bahwa rutinitas seorang Sobrinudin pada pagi hari ialah mengantar keponakannya walaupun dengan berjalan kaki karena tidak bisa menaiki sepeda (Hirata, 2017:24)

Tokoh Sobrinudin memiliki rasa cinta kepada kedua keponakannya. Sobrinudin tidak dapat naik sepeda. Meskipun hanya berjalan kaki, dia tetap mau mengantar keponakannya ke 
sekolah setiap hari. Ekpresi cinta kepada keluarga juga tampak pada kutipan di bawah ini.

"Bu, aku mau minta izin untuk tidak sekolah esok karena mau menemani ibuku untuk sebuah acara yang sangat penting. Tak ada lagi laki-laki dalam keluarga kami, aku harus mengantar ibuku," ujar Tegar kelas 5 SD, santai tapi serius.

Tegar meminta izin untuk tidak masuk sekolah esok hari sebab akan mengantar ibunya ke pengadilan. Tegar adalah anak sulung. Dia merupakan laki-laki satusatunya dalam keluarganya. Dalam kondisi dan situasi seperti itu Tegar harus mendampingi ibunya karena ia adalah anak tertua dalam keluarganya walupun ia masih kelas lima SD. Pekerjaan apa pun dilakukan Tegar asalkan dia mendapatkan uang dari hasil kerjanya, termasuk berjualan minuman di Stadion Belantik (Hirata, 2017:37).

Kutipan tersebut menggambarkan tokoh Tegar yang mencintai keluarganya. Hal ini ditunjukkan dengan kesediaan Tegar mendampingi sang ibu ke pengadilan. Saat itu, mereka bermaksud mengurus perceraian ibu dan ayah Tegar.

Ekspresi cinta keluarga juga tampak pada tokoh Ayah yang digambarkan dalam novel. Sang Ayah selalu bekerja banting tulang mencari nafkah untuk keluarganya. Sang Ayah bekerja serabutan. Tokoh Ayah selalu bekerja apa pun untuk mencukupi kebutuhan sehari-hari sebagai bentuk cintanya terhadap keluarga.

\section{Cinta kepada Perdamaian}

Cinta perdamaian merupakan suatu tingkah laku dan sikap yang menggambarkan situasi aman dan nyaman, tenang, serta tenteram terhadap diri sendiri dalam suatu organisasi atau lingkungan masyarakat.

Rasa cinta damai tergambarkan juga dalam novel Sirkus Pohon. Orang tua Tara berpisah dengan cara yang baik. Hal itu terkandung dalam penggalan kalimat ketika ayah dan ibu Tara memutuskan untuk berpisah. Ketika itu, tidak ada yang bertengkar. Semuanya berjalan dengan baik hingga proses persidangan selesai. Hal tersebut mencerminkan cinta keduanya kepada perdamaian.

Perilaku ibu Tara mencerminkan bahwa dia adalah orang yang cinta terhadap perdamaian. Dia bersedia menerima segala kondisi. Tidak ada pertengkaran di antara ayah dan ibu Tara hingga akhirnya mereka memutuskan untuk berpisah. Bahkan, saat ayah Tara ditagih oleh penagih utang, ibu Tara-lah yang membayar semua utang tersebut dengan sukarela. Ibu Tara tidak menuntut balasan apa-apa.

\section{Cinta kepada Masyarakat Sekitar}

Cinta kepada masyarakat sekitar merupakan suatu gambaran yang memperlihatkan kepedulian manusia kepada orang lain. Cinta terhadap masyarakat sekitar tergambar dalam novel karya Andrea Hirata ini dengan memperlihatkan sosok ayah yang memperoleh bantuan dari kantor desa untuknya. Akan tetapi, bantuan itu ditolak ayah Tara. Hal itu terdapat dalam kutipan berikut.

\footnotetext{
"Dengan santun, ayah menolak stiker itu. Katanya banyak keluarga lain yang lebih perlu stiker itu. Katanya lagi, kami miskin, tapi masih punya penghasilan walaupun tidak banyak." (Hirata, 2017:37)
}

Penolakan ayah yang tergambar dalam kalimat tersebut merupakan rasa cinta ayah kepada masyarakat sekitar. Ayah 
beranggapan bahwa masih banyak kepala keluarga yang membutuhkan bantuan tersebut daripada dirinya. Sosok ayah digambarkan sebagai tokoh yang masih mampu bekerja dengan sekuat tenaga. Ayah tidak mengharapkan bantuan dari pemerintah. Keadaan ini membuat ayah bersimpati kepada orang lain yang hidupnya lebih miskin daripada dirinya.

\section{Cinta kepada Tanah Air}

Cinta tanah air merupakan keadaan cara berpikir manusia, berperilaku, dan perbuatan yang mencerminkan kesetiaan, kepedulian antarsesama, serta penghormatan terhadap lingkungan, budaya, ekonomi, dan politik. Pada hakikatnya, cinta terhadap tanah air ialah rela berkorban demi persatuan bangsa.

Cinta tanah air diwujudkan dalam keseharian setiap individu, baik kepada masyarakat, keluarga, maupun organisasi. Perilaku dan sikap cinta kepada tanah air terlihat dalam sosok ibu Tara yang menggelar pertunjukan sirkus dengan mengambil kisah Raja Berekor yang merupakan cerita legenda dari Belitung.

Sikap ibu Tara tersebut mencerminkan bahwa ia sangat mencintai tanah air. Ia menggelar pertunjukan teater lokal dan memberikan pengetahuan serta ilmu tentang budaya daerahnya kepada setiap orang. Dalam novel Sirkus Pohon, dikatakan bahwa seni pertunjukan teater dari Boncel ialah teater sirkus Raja Berekor. Penonton yang melihat aksi pertunjukan tersebut terpukau atas pertunjukannya.

Raja Berekor merupakan cerita legenda dari daerah Belitung yang mengisahkan sosok raja zalim yang menguasai daerah di wilayah Belitung sampai Palembang. Sosok raja zalim digambarkan gagah berani dan kuat. Akan tetapi, dia membuat suatu kesalahan dengan melakukan perbuatan yang tidak terpuji, yakni memakan daging manusia.

Cinta kepada tanah air yang lain terlihat dari kutipan yang mengatakan bahwa sosok ibu Tara sangat antusias dalam mengembangkan budaya daerah melalui aksi pertunjukan teater. Kondisi ini didukung oleh animo masyarakat dan peminat pertunjukan seni teater yang sangat banyak. Ibu Tara sangat antusias dan berupaya mengembangkan kisah tersebut. Ibu Tara memfokuskan segalanya untuk menulis skenario dan dialog agar lebih mudah merasuk ke dalam hati penonton. Ia juga membuat properti yang digunakan dalam pertunjukan. Bahkan, dia tidak lupa mencari pemeran utama dalam teater tersebut.

\section{Cinta kepada Lingkungan}

Cinta kepada lingkungan berarti memiliki rasa kepedulian kepada lingkungan, yakni perilaku dan perbuatan yang berusaha membangun dan membudayakan menjaga lingkungan. Pada novel Sirkus Pohon, bukti cinta terhadap lingkungan tecermin dalam sosok Sobri, yakni ketika tokoh Sobri melamar Dinda. Saat itu, Dinda memakai pakaian serba hijau yang identik dengan warna alam lingkungan. Mulai dari jilbab sampai sapu tangan yang dikenakan oleh Dinda, semuanya berwarna hijau.

Berdasarkan kalimat tersebut, Hirata mencoba membawa pembaca untuk melihat keadaan lingkungan. Manusia yang cinta kepada lingkungan haruslah menjaganya dengan baik.

\section{Cinta kepada Lawan Jenis}

Perasaan cinta merupakan proses yang muncul dan tumbuh dengan sendirinya. Seseorang yang mengalami jatuh cinta 
dapat bertindak di luar akal sehat, dapat berbuat hal-hal aneh dan konyol. Hal tersebut menggambarkan perasaan seseorang saat menyukai orang lain.

Saat jatuh cinta, ada rasa memiliki dan dimiliki seutuhnya. Cinta yang sejati merupakan sesuatu yang tidak dapat tergambarkan dan didambakan kehadirannya. Jatuh cinta kepada lawan jenis adalah hal yang wajar. Dalam novel Sirkus Pohon dikatakan bahwa Sobri ikhlas, gembira, serta bahagia menerima keadaan Dinda, seperti janji Sobri kepada dirinya sendiri yang tidak akan bersedih selama 40 hari. Sobri mencoba mencontoh ayahnya yang selalu tabah dan ikhlas. Hal itulah yang coba diikuti oleh Sobri.

Dinda yang tiba-tiba hilang ingatan tidak menyurutkan rasa cinta Sobri kepadanya. Sobri mau menerima Dinda dalam keadaan apa pun. Ini adalah bentuk ekpsresi cinta Sobrinudin terhadap Dinda. Rasa cintanya terhadap Dinda dibuktikan lagi dengan melamar Dinda. Keluarga Sobri membawa kue khas Melayu yang merupakan salah satu adat ketika proses lamaran berlangsung. Pernyataan tersebut adalah ekspresi cinta tokoh Sobrinudin terhadap Dinda. Keseriusannya dibuktikan dengan melamar Dinda menjadi istrinya meskipun Dinda dalam keadaan sakit.

\section{PENUTUP}

Berdasarkan analisis yang telah dilakukan, penulis menyimpulkan bahwa wujud ekspresi cinta yang termuat dalam novel Sirkus Pohon karya Andrea Hirata meliputi (1) cinta kepada Tuhan yang digambarkan oleh tokoh Ibu, (2) cinta kepada sahabat yang digambarkan tokoh Taripol, (3) cinta kepada keluarga yang digambarkan oleh tokoh Ayah dan Tegar, (4) cinta kepada perdamaian yang digambarkan oleh Ibu Tara, (5) cinta kepada masyarakat sekitar yang digambarkan oleh tokoh Ayah, (6) cinta kepada tanah air yang digambarkan oleh Ibu Tara, (7) cinta kepada lingkungan yang digambarkan oleh tokoh Dinda dan Sobirinudin, dan (8) cinta kepada lawan jenis antara Sobirinudin dan Dinda.

\section{DAFTAR PUSTAKA}

Hirata, A. (2017). Sirkus Pohon. Yogyakarta: Bentang.

Nurgiyantoro, B. (2010). Teori Pengkajian Fiksi. Yogyakarta: Gadjah Mada University Press.

Sarwiningsih, Y. (2013). Demistifikasi Cinta dalam Cerkak-Cerkak pada Majalah Panjebar Semangat. Journal of Javanese Literature, 2(1).

Simangungsong, N. (2015). Kekuatan Cinta dalam Novel "Habibie dan Ainun" Karya Bacharudin Jusuf Habibie. Universitas Sumatra Utara.

Siregar, R. K. (2013). Metafora Cinta dalam Bahasa Angkola. Universitas Sumatra Utara.

Sri Susetianingsih, T. (2016). Ekspresi Cinta pada Novel BidadariBidadari Karya Tere Liye. Journal of Indonesian Language Education and Literature, 1(2). http://www.syekhnurjati.ac.id/jurn al/index.php/jeill/ https://doi.org/10.24235/ileal.v1i2. 609

Wattimena, F. (2014). Kekuatan Cinta yang Tercermin dalam Cerita Pendek Brokeback Mountain dan A Type of Love Story. Jurnal Elektronik Fakultas Sastra Universitas Sam Ratulangi, 2(2). 